\title{
The effect of COVID-19 pandemic on inguinal hernia emergencies
}

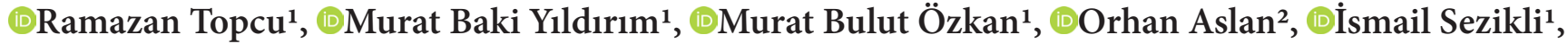 \\ (D)Fatih Şahin ${ }^{1}$ \\ ${ }^{1}$ Hitit University, Faculty of Medicine, Department of General Surgery, Çorum, Turkey \\ ${ }^{2}$ Hitit University, Erol Olçok Training and Research Hospital, General Surgery Clinic, Çorum, Turkey
}

Cite this article as: Topcu R, Ylldırım MB, Özkan MB, Aslan O, Sezikli İ, Şahin F. The effect of COVID-19 pandemic on inguinal hernia emergencies. J Health Sci Med 2021; 4(6): 865-870.

\begin{abstract}
Introduction: COVID-19 has spread all over the world and caused significant changes in healthcare practices. This is why many expert associations have published new guidelines on COVID-19 management. This study aims to investigate whether the COVID-19 pandemic has an effect on Inguinal hernia (IH) emergencies.

Material and Method: A total of 63 patients diagnosed with strangulated/incarcerated inguinal hernia who presented to the emergency surgery department of our hospital between April 2020 and January 2021 during the pandemic (DP) and between April 2019 and January 2020 before the pandemic (BP) were retrospectively analyzed and compared.

Results:There was no statistically significant difference between both groups in terms of demographic characteristics. The comparison of the number of admissions, admission time, anesthesia type, hospital stay, postoperative complications, ASA score, hernia, WBC, and CRP averages showed no statistically significant difference between the groups. Moreover, there was no statistically significant difference between the two groups in terms of distributions of hernia types, hernia repair types, mesh use, and additional resection requirement. The comparison of the patients who underwent organ resection by admission time in both groups showed no statistically significant difference. It was observed that the number of patients who required small bowel resection were especially high on the 4 th day. In DP, small bowel resection was performed on 4 (66.7\%) patients and omentectomy was performed in $2(33.3 \%)$ patients. In BP, only one right hemicolectomy was performed. The comparison of the patients with an admission time of 4 th day revealed a statistically significant difference $(\mathrm{p}=0.03)$.

Conclusion: We observed that morbidity increased as the admission time was delayed. Anticipating that the fear of COVID-19 infection will hold back the emergency response during the pandemic period, patients should be informed not to delay early diagnosis and treatment.
\end{abstract}

Keywords: COVID -19 pandemic, emergency, inguinal hernia

\section{INTRODUCTION}

Coronavirus disease (COVID-19) is an infectious disease caused by the SARS-CoV-2 virus. In December 2019, the World Health Organization declared a covid 19 epidemic. Most COVID-19 patients battle a mild or moderate prognosis, with up to $5-10 \%$ going to have a severe, potentially trying course (4). The tide of death is approaching fast, the queue is easy to mess with and it's about close-up events and concerns at close proximity (5).

The COVID-19 pandemic has taken the whole world under its influence in a short time, and unexpected and unprecedented radical changes in health practices have affected all countries. During the COVID-19 pandemic, surgical units gave priority to emergency procedures and oncological cases and postponed elective cases (6).

Abdominal hernia surgery is one of the most performed surgeries with a rate of 100 to 500 cases per 100,000 per year $(7)$. While mortality rates are around $0.5 \%$ in elective hernia surgery, it is around $5 \%$ in emergency cases (8). In the cases of incarceration or strangulation, although the final treatment is often surgical, a decision must be made based on the patient's condition (age, accompanying diseases, Computed Tomography finding, SIRS, etc.). If there is a high probability of strangulation, the decision should an urgent surgery. 
The goals of emergency hernia surgery can be divided into three parts: saving lives (gangrenous bowel/tissue resection); restoring GI continuity (if bowel resection was performed); repairing the abdominal wall. These goals can be achieved in the same operation, yet a phased approach may also be required. Mortality and morbidity in the emergency department increase 10-20 times compared to elective surgery, and bowel infarction is the major risk factor for this (9).

Inguinal hernia $(\mathrm{IH})$ is a common pathology that has the risk of developing significant complications in the case of strangulation. Strangulated inguinal hernias are a surgical emergency and are associated with high morbidity and mortality $(10,11)$. Delayed diagnosis of patients with incarcerated/strangulated inguinal hernia and not performing surgery in the first 24 hours are associated with increased bowel resection. Therefore, early diagnosis of these patients and timing of treatment gain importance.

This study aims to investigate the effect of the pandemic on inguinal hernia emergencies.

\section{MATERIAL AND METHOD}

The study was approved by the Hitit University Noninterventional Researchs Ethics Committee (Date: 30.04.2021, Decision No:2021-66). All procedures were carried out in accordance with the ethical rules and the principles of the Declaration of Helsinki. Strangulated/ incarcerated inguinal hernia patients presented to the emergency department and operated during the April 2019-December 2019 pre-pandemic (BP) period and the April 2020-December 2020 pandemic period (DP) were retrospectively analyzed.

Patients presented to the emergency department of the Hitit University Erol Olçok Training and Research Hospital General Surgery Clinic and operated for incarcerated/ strangulated inguinal hernia between the specified dates were retrospectively searched from the hospital system. The data of 63 patients were retrieved. The patients were divided into two groups as BP and DP. There were 35 patients in the BP group and 28 patients in the DP group. The patients' gender, age at admission, comorbidities, ASA scores, presence of ileus symptoms, number of days from incarceration to admission, presence of air-fluid level on erect abdominal radiograph (EAR), white blood cell count (WBC), C-reactive peptide (CRP) level, albumin (Alb) level, hernia type (indirect, direct, femoral), type of surgery performed (anterior repair, McVay, Plug Mesh), mesh use, type of anesthesia used, whether resection was performed, operative time, presence of perioperative morbidity, local complications during hospitalization and length of stay were found from the Hospital Information Management System and included in the study.
Numerical variables such as age, time to admission, WBC, CRP, operative time, length of stay were reported using the mean \pm standard deviation and median in parentheses. Correlations between numerical measurements were assessed with Pearson or Spearman correlation coefficient in accordance with the data distribution. Categorical variables such as gender, number of comorbidities, ASA score, presence of ileus symptoms, presence of air-fluid level, type of hernia and type of surgery, presence of mesh, anesthesia type, resection type, perioperative morbidity, and local complications were reported as numbers and percentages in parentheses. Normally distributed data were evaluated using the Shapiro-Wilk test. Statistical differences between age, time to admission, CRP, operative time, and length of stay were evaluated with the Mann-Whitney-U test. Ratio comparisons and correlation analyses of categorical variables according to study groups were performed using the Chisquare and Fisher's exact tests. The level of statistical significance was set at $\mathrm{p}<0.05$. All statistical analyses were performed using IBM SPSS Statistics for Windows software (version 26; IBM Corp., Armonk, N.Y., USA).

\section{RESULTS}

Of the 63 patients included in the study, 50 were male $(79.4 \%)$, with a mean age of $68.21 \pm 17.89$ years. The median age was 74 years, the youngest patient was 23 years old, and the oldest patient was 94 years old.

There were 32 patients $(50.8 \%)$ who had no disease in the entire group, $23(36.5 \%)$ of the patients were evaluated as ASA2, 27 (42.9\%) as ASA3, and $13(20.6 \%)$ as ASA4.

The patients presented to the hospital $2 \pm 0.89$ days after the onset of symptoms, 39 patients $(61.9 \%)$ had ileus symptoms at admission, but only $30(47.6 \%)$ had airfluid levels on EAR. The mean and standard deviations of $\mathrm{WBC}$ and CRP of the patients at admission were $9.23 \pm 3.40109 / \mathrm{L}, 20.17 \pm 45.03 \mathrm{mg} / \mathrm{dL}$, respectively.

The majority of the patients (41 patients (65.1\%)) were evaluated to have an indirect hernia. While 53 (84.1\%) hernias were repaired with the anterior approach, 6 (9.5\%) were repaired with McVay repair, and 4 (6.3\%) with Mesh Plug technique. The rate of mesh use was calculated as $85.7 \%$, with 54 patients. Omentectomy was added to the repair of 7 patients (11.1\%), small bowel resection was performed on $8(12.7 \%)$ patients, primary repair of the colon was performed on 1 (1.6\%) patient, and right hemicolectomy was performed on 1 (1.6\%). Most of the operations $(76.2 \%$ (46)) were performed under spinal anesthesia, with a mean operative time of $80.40 \pm 25$ minutes. 
In the perioperative period, acute renal failure (ARF) was observed in 2 patients, postoperative ileus in 1 patient, cerebrovascular disease (CVD) in 1 patient, thrombocytopenia in 1 patient, and COVID-19 positivity in 2 patients. Among all patients, 1 seroma, 1 hematoma, and 1 intra-abdominal hematoma were observed. The patients were discharged after a mean length of hospital stay of $4.05 \pm 2.64$ days postoperatively (Table 1 ).

\begin{tabular}{|c|c|}
\hline & $\begin{array}{c}\text { Whole Group } \\
\text { (Median/Percent) } \\
(n=63)\end{array}$ \\
\hline \multicolumn{2}{|l|}{ Gender } \\
\hline Male & $50(79.4 \%)$ \\
\hline Female & $13(20.6 \%)$ \\
\hline Age (years) & $68.21 \pm 17.89(74)$ \\
\hline \multicolumn{2}{|l|}{ Number of Comorbidities } \\
\hline 0 & $32(50.8 \%)$ \\
\hline 1 & $12(19.0 \%)$ \\
\hline 2 & $12(19.0 \%)$ \\
\hline 3 & $7(11.1 \%)$ \\
\hline \multicolumn{2}{|l|}{ ASA } \\
\hline 2 & $23(36.5 \%)$ \\
\hline 3 & $27(42.9 \%)$ \\
\hline 4 & $13(20.6 \%)$ \\
\hline Ileus Symptoms & $39(61.9 \%)$ \\
\hline Time to Admission (Days) & $2 \pm 0.89(2)$ \\
\hline Air Fluid Level in EAR & $30(47.6 \%)$ \\
\hline WBC & $9.23 \pm 3.40(9.08)$ \\
\hline CRP & $20.17 \pm 45.03(3.50)$ \\
\hline \multicolumn{2}{|l|}{ Type of Hernia } \\
\hline Indirect & $41(65.1 \%)$ \\
\hline Direct & $9(14.3 \%)$ \\
\hline Femoral & $13(20.6 \%)$ \\
\hline \multicolumn{2}{|l|}{ Type of Surgery } \\
\hline Anterior & $53(84.1 \%)$ \\
\hline McVay & $6(9.5 \%)$ \\
\hline Plug Mesh & $4(6.3 \%)$ \\
\hline Presence of Mesh & $54(85.7 \%)$ \\
\hline \multicolumn{2}{|l|}{ Type of Anesthesia } \\
\hline Spinal & $48(76.2 \%)$ \\
\hline General & $15(23.8 \%)$ \\
\hline \multicolumn{2}{|l|}{ Type of Resection } \\
\hline Omentectomy & $7(11.1 \%)$ \\
\hline Small Bowel Resection & $8(12.7 \%)$ \\
\hline Primary Repair of Colon & $1(1.6 \%)$ \\
\hline Right Hemicolectomy & $1(1.6 \%)$ \\
\hline \multicolumn{2}{|l|}{ Postoperative Complications } \\
\hline ARF & $2(3.2 \%)$ \\
\hline Ileus & $1(1.6 \%)$ \\
\hline CVD & $1(1.6 \%)$ \\
\hline Thrombocytopenia & $1(1.6 \%)$ \\
\hline COVID-19 & $2(3.2 \%)$ \\
\hline \multicolumn{2}{|l|}{ Local Complications } \\
\hline Intraabdominal Hematoma & $1(1.6 \%)$ \\
\hline Hematoma & $1(1.6 \%)$ \\
\hline Seroma & $1(1.6 \%)$ \\
\hline Length of Hospital Stay (days) & $4.05 \pm 2.64(3)$ \\
\hline
\end{tabular}

The patients were divided into two groups as BP and DP. The comparison of the distribution of gender, age, number of comorbidities, and ASA scores in the two groups showed no statistically significant difference (Table 1).

The mean time to admission was $1.77 \pm 0.64$ days in the BP group and $2.29 \pm 1.08$ days in the DP group, with no significant difference between the two periods $(\mathrm{p}=0.066)$. Ileus symptoms were present in 60\% (21) of the patients presented BP and in $64.3 \%$ (18) of the patients presented DP, with no statistically significant difference $(\mathrm{p}=0.798)$. Air-fluid levels were observed in $19(54.3 \%)$ patients in the pre-COVID-19 period and in $11(39.9 \%)$ patients in the post-COVID-19 period, but there was no significant difference $(\mathrm{p}=0.312)$.

The comparison of the mean $\mathrm{WBC}$ and CRP values of the patients in both groups showed no statistically significant difference (Table 2). Moreover, no statistically significant difference was observed between the two groups in terms of distributions of hernia types, hernia repair types, mesh use, and additional resection requirement (Table 2).

The comparison of the anesthesia type in the $\mathrm{BP}$ and DP groups showed that the rate of preferring spinal anesthesia was $71.4 \%$ in $\mathrm{BP}$, whereas this rate increased to $82.1 \%$ in the post-COVID-19 period, though no statistically significant difference was found $(\mathrm{p}=0.383)$. The mean operative times were $80.00 \pm 28.64$ minutes (75) and $80.89 \pm 20.04$ (75) minutes in BP and DP, respectively, with no significant difference $(\mathrm{p}=0.487)$. The distribution of postoperative and local complications between the two periods was not statistically significant $(\mathrm{p}=0.189, \mathrm{p}=0.168$, respectively).The mean length of stay was $3.74 \pm 2.79$ (3) days in the BP group and $4.43 \pm 2.45$ (4) days in the DP group, with no statistically significant difference $(\mathrm{p}=0.068)$ (Table 2).

The difference between the patients who underwent organ resection by admission time was not statistically significant (Table 3).It was observed that the number of patients who required small bowel resection were especially high on the 4th day. In DP, small bowel resection was performed on $4(66.7 \%)$ patients and omentectomy was performed in $2(33.3 \%)$ patients. In $\mathrm{BP}$, only one right hemicolectomy was performed. The comparison of the patients with an admission time of 4th day revealed a statistically significant difference $(\mathrm{p}=0.03)($ Table 4$)$. 
Table 2. Comparison of patients before and after COVID-19

Whole Group (Median/Percent) $(\mathrm{n}=63)$

\begin{tabular}{|c|c|c|c|}
\hline & BP-group $1(n=35)$ & DP- group $2(n=28)$ & P-value \\
\hline \multicolumn{4}{|l|}{ Gender } \\
\hline Male & $30(85.7 \%)$ & $20(71.4 \%)$ & $\mathrm{p}=0.215$ \\
\hline Female & $5(14.3 \%)$ & $8(28.6 \%)$ & \\
\hline Age (years) & $66.83 \pm 19.89(74)$ & $69.93 \pm 15.20(72.5)$ & $\mathrm{p}=0.729$ \\
\hline \multicolumn{4}{|l|}{ Number of Comorbidities } \\
\hline 0 & $17(48.6 \%)$ & $15(53.6 \%)$ & $\mathrm{p}=0.760$ \\
\hline 1 & $7(20.0 \%)$ & $5(17.9 \%)$ & \\
\hline 2 & $8(22.9 \%)$ & $4(14.3 \%)$ & \\
\hline 3 & $3(8.6 \%)$ & $4(14.3 \%)$ & \\
\hline \multicolumn{4}{|l|}{ ASA Score } \\
\hline 2 & $14(40 \%)$ & $9(32.1 \%)$ & $\mathrm{p}=0.807$ \\
\hline 3 & $14(40 \%)$ & $13(46.4 \%)$ & \\
\hline 4 & $7(20 \%)$ & $6(21.4 \%)$ & \\
\hline Ileus Symptoms & $21(60 \%)$ & $18(64.3 \%)$ & $\mathrm{p}=0.798$ \\
\hline Time to Admission (Days) & $1.77 \pm 0.64(2)$ & $2.29 \pm 1.08(2)$ & $\mathrm{p}=0.066$ \\
\hline Air Fluid Level in EAR & $19(54.3 \%)$ & $11(39.9 \%)$ & $\mathrm{p}=0.312$ \\
\hline WBC (109/L) & $8.87 \pm 2.94(9.09)$ & $9.68 \pm 3.91(9.01)$ & $\mathrm{p}=0.352$ \\
\hline CRP (mg/dL) & $19.81 \pm 43.75$ & $20.63 \pm 47.37(4.30)$ & $\mathrm{p}=0.352$ \\
\hline \multicolumn{4}{|l|}{ Type of Hernia } \\
\hline Indirect & $24(68.6 \%)$ & $17(60.7 \%)$ & $\mathrm{p}=0.736$ \\
\hline Direct & $5(14.3 \%)$ & $9(14.3 \%)$ & \\
\hline Femoral & $6(17.1 \%)$ & $13(20.6 \%)$ & \\
\hline \multicolumn{4}{|l|}{ Type of Surgery } \\
\hline Anterior & $30(85.7 \%)$ & $23(82.1 \%)$ & $\mathrm{p}=0.928$ \\
\hline McVay & $3(8.6 \%)$ & $6(9.5 \%)$ & \\
\hline Plug Mesh & $2(5.7 \%)$ & $4(6.3 \%)$ & \\
\hline Presence of Mesh & $32(91.4 \%)$ & $22(78.6 \%)$ & $\mathrm{p}=0.170$ \\
\hline \multicolumn{4}{|l|}{ Type of Anesthesia } \\
\hline Spinal & $25(71.4 \%)$ & $23(82.1 \%)$ & $\mathrm{p}=0.383$ \\
\hline General & $10(28.6 \%)$ & $5(17.9 \%)$ & \\
\hline \multicolumn{4}{|l|}{ Type of Resection } \\
\hline Omentectomy & $3(8.6 \%)$ & $4(14.3 \%)$ & $\mathrm{p}=0.704$ \\
\hline Small Bowel Resection & $4(11.4 \%)$ & $4(14.3 \%)$ & \\
\hline Primary Repair of Colon & $1(2.9 \%)$ & $0(0 \%)$ & \\
\hline Right Hemicolectomy & $1(2.9 \%)$ & $0(0 \%)$ & \\
\hline Operative Time (min) & $80.00 \pm 28.64(75)$ & $80.89 \pm 20.04(75)$ & $\mathrm{p}=0.487$ \\
\hline \multicolumn{4}{|l|}{ Perioperative Morbidity } \\
\hline ARF & $2(5.7 \%)$ & $0(0 \%)$ & $\mathrm{p}=0.189$ \\
\hline Ileus & $0(0 \%)$ & $1(3.6 \%)$ & \\
\hline CVD & $0(0 \%)$ & $1(3.6 \%)$ & \\
\hline Thrombocytopenia & $1(2.9 \%)$ & $0(0 \%)$ & \\
\hline COVID-19 & $0(0 \%)$ & $2(7.1 \%)$ & \\
\hline \multicolumn{4}{|l|}{ Local Complications } \\
\hline Intraabdominal Hematoma & $0(0 \%)$ & $1(3.6 \%)$ & $\mathrm{p}=0.168$ \\
\hline Hematoma & & $1(3.6 \%)$ & \\
\hline Seroma & & $1(3.6 \%)$ & \\
\hline Length of Hospital Stay (days) & $3.74 \pm 2.79(3)$ & $4.43 \pm 2.45(4)$ & $\mathrm{p}=0.068$ \\
\hline
\end{tabular}

\begin{tabular}{|c|c|c|c|c|}
\hline \multirow{2}{*}{$\begin{array}{c}\text { Admission } \\
\text { Day }\end{array}$} & \multirow[b]{2}{*}{ Resection } & \multicolumn{2}{|c|}{$\begin{array}{c}\text { Whole Group } \\
(n=63)\end{array}$} & \multirow[b]{2}{*}{$\begin{array}{l}\text { Statistical } \\
\text { Significance }\end{array}$} \\
\hline & & $\begin{array}{c}\text { Pre- } \\
\text { COVID-19 } \\
(n=35)\end{array}$ & $\begin{array}{c}\text { Time of } \\
\text { COVID-19 } \\
(n=28)\end{array}$ & \\
\hline \multirow{2}{*}{1} & No & $10(90.9 \%)$ & $7(100 \%)$ & \multirow{2}{*}{$\mathrm{p}=1$} \\
\hline & Yes & $1(9.1 \%)$ & $0(0 \%)$ & \\
\hline \multirow{2}{*}{2} & No & $16(72.7 \%)$ & $11(91.7 \%)$ & \multirow{2}{*}{$\mathrm{p}=0.378$} \\
\hline & Yes & $6(27.3 \%)$ & $1(8.3 \%)$ & \\
\hline \multirow{2}{*}{3} & No & $0(0 \%)$ & $2(66.7 \%)$ & \multirow{2}{*}{$\mathrm{p}=1$} \\
\hline & Yes & $1(100 \%)$ & $1(33.3 \%)$ & \\
\hline \multirow{2}{*}{4} & No & $0(0 \%)$ & $0(0 \%)$ & \multirow{2}{*}{ * } \\
\hline & Yes & $1(100 \%)$ & $6(100 \%)$ & \\
\hline
\end{tabular}

\begin{tabular}{|c|c|c|c|c|}
\hline \multirow[b]{2}{*}{$\begin{array}{c}\text { Admission } \\
\text { Day }\end{array}$} & \multirow[b]{2}{*}{$\begin{array}{l}\text { Type of } \\
\text { Resection }\end{array}$} & \multicolumn{2}{|c|}{ Whole Group $(n=7)$} & \multirow[b]{2}{*}{$\begin{array}{c}\text { Statistical } \\
\text { Significance }\end{array}$} \\
\hline & & $\begin{array}{c}\text { Pre- } \\
\text { COVID-19 } \\
(n=1)\end{array}$ & $\begin{array}{c}\text { Time of } \\
\text { COVID-19 } \\
(n=6)\end{array}$ & \\
\hline \multirow{3}{*}{4} & Omentectomy & $0(0 \%)$ & $2(33.3 \%)$ & \multirow{3}{*}{$(p=0.03)$} \\
\hline & $\begin{array}{l}\text { Small Bowel } \\
\text { Resection }\end{array}$ & $0(0 \%)$ & $4(66.7 \%)$ & \\
\hline & $\begin{array}{l}\text { Right } \\
\text { Hemicolectomy }\end{array}$ & $1(100 \%)$ & $0(0 \%)$ & \\
\hline
\end{tabular}




\section{DISCUSSION}

Patients presenting with acute inguinal hernia (IH) remain a common surgical emergency. The popular "watch and wait" policy for IH increases the immediate presentation of such hernias. The management of such patients is associated with significant morbidity, and indeed mortality (12). It is known that especially age $>65$ years, prolonged symptom duration, delay in admission, diagnosis and surgery, time from admission to surgery, strangulation more than 24 hours, symptom duration of 3 days or longer, femoral hernia, female gender, ASA class III and IV, and ileus increase mortality and morbidity in patients (11). The COVID-19 pandemic has taken the whole world under its influence in a short time, and unexpected and unprecedented radical changes in health practices have affected all countries. During the COVID-19 pandemic, surgical units gave priority to emergency procedures and oncological cases and postponed elective cases (6). Emergency IH is considered one of the most common emergency surgeries performed in any surgical department because of the high risk of morbidity and mortality associated with delayed repair. On the other hand, elective hernia repair for uncomplicated hernias has been postponed at our institution and in many countries of the world to reduce the risk of viral transmission to operating room personnel and other patients. Therefore, we anticipated an increase in the number of hernia-related complications following the cancellation of elective procedures. However, in DP, the number of emergency applications has decreased in general and a significant decrease has been observed in emergency IHs. However, a study based on German data reported that the decrease in elective inguinal hernia repairs was almost $70 \%$ in the weeks when the pandemic reached its peak, however, contrary to expectations, the rate of emergency inguinal hernia surgery did not increase (13). In this study, the number of patients admitted to our institution with the diagnosis of emergency IH in DP and BP was not statistically significant between both groups. While the number of applications to hospital emergencies decreased all over the world, it is seen that the number of applications for inguinal hernia emergencies was not affected in the Germany study. While our study was compatible with the German study, it was not compatible with other studies.

During the pandemic period, patients were concerned about the risk of COVID-19 infection, and the rate of admissions to hospital emergency departments decreased $(14,15)$. Therefore, the admission time and the duration of strangulation were expected to increase emergency IHs. However, in general, this study found no statistically significant difference in terms of admission time to the emergency departments s of hospitals in DP and BP. Nevertheless, when the admission times were evaluated separately, there was a significant difference between the two groups in terms of patients who had small bowel resection on the 4 th day $(\mathrm{p}=0.03)$. We think that this result is probably caused by late admission to the hospital due to the risk of COVID-19 infection .

In this study, the number of patients admitted to our institution with the diagnosis of emergency IH in DP and BP was not statistically significant between both groups. In DP, the number of emergency admissions has generally decreased in the world, and there has been a significant decrease in emergency IHs (14). There was no significant difference between the groups in terms of age, hernia type, admission time, and ileus presentation, which affect the mortality of emergency IHs. There was no statistically significant difference between the two groups in terms of the length of hospital stay, local complications, requirement for organ resection, ASA score, selection of anesthesia type, and operative time.

As it is known, SARS-CoV-2 is a virus transmitted by aerosol droplets. Although it has been isolated from many body fluids such as feces, urine and blood, no definite evidence has yet been revealed in terms of direct transmission from the peritoneal cavity. However, it is a fact that has been revealed a long time ago that viruses of similar nature can be transmitted through surgical smoke $(16,17)$.In the guideline published by the European Hernia Society for hernia surgery in adult patients during the COVID-19 pandemic, it is recommended to decide on the use of laparoscopy in emergency cases by considering the balance between risks and benefits.In addition, in the guide published by China in February, the concern that laparoscopy in COVID $(+)$ patients may cause additional lung damage to the existing viral damage through increased intra-abdominal pressure was brought to the agenda. Although this idea remained more of a theoretical hypothesis, it has become a new topic of discussion (18). In this study, direct open surgery was performed in all patients with DP and spinal anesthesia was performed. An important factor in this choice was the concern that pneumoperitoneum desufflation created during laparoscopic surgery might increase viral aerosolization. Moreover, the fact that laparoscopy made general anesthesia inevitable came to the fore as an important factor.In this study, there was no significant difference in terms of anesthesia choice in $\mathrm{PE}$ and DP, and the patients were operated under spinal anesthesia in general. Since laparoscopy was used less in both periods, spinal surgery was preferred, especially in DP, to minimize the risk of transmission during intubation.

All patients waiting for elective surgery are important and should be assured. Most of the time, delay in elective 
hernia repair may not cause an increase in the risk of complications; nevertheless, patients should be informed about possible complications in case of delay, and the conditions that require admission to the emergency department should be explained thoroughly to ensure that early diagnosis and treatment are not delayed. The role of not delaying emergency services during the pandemic, the correct management of elective surgical procedures in the pre-pandemic period, and rapid diagnosis and use of treatment protocols by surgeons during the pandemic period are important $(18,19)$.

Although there were curfew restrictions during the pandemic period in our country, we think that treatments have been effectively administered without delays and disruptions in the case of surgical emergencies. Pandemicrelated morbidity and mortality rates of hernia surgery can be reduced by taking patient-hospital oriented preventive measures to reduce viral transmission. Early diagnosis and treatment undertake a key role.

\section{CONCLUSION}

During the pandemic period, elective surgical procedures should be managed accurately, patients should be informed about possible complications in case of delay, and the conditions that require admission to the emergency department should be explained thoroughly to patients. We observed that morbidity increased as the admission time was delayed. Anticipating that the fear of COVID-19 infection will hold back the emergency response during the pandemic period, patients should be informed not to delay early diagnosis and treatment.

\section{ETHICAL DECLARATIONS}

Ethics Committee Approval: The study was approved by the Hitit University Non-interventional Researchs Ethics Committee (Date: 30.04.2021, Decision No: 2021-66).

Informed Consent: All patients signed the free and informed consent form.

Referee Evaluation Process: Externally peer-reviewed.

Conflict of Interest Statement: The authors have no conflicts of interest to declare.

Financial Disclosure: The authors declared that this study had received no financial support.

Author Contributions: All of the authors declare that they have all participated in the design, execution, and analysis of the paper and approved the final version.

Acknowledgment: This article was presented at the $8^{\text {th }}$ Virtual National Hernia Congress. (11-12 March 2021, SB-13 )

\section{REFERENCES}

1. Coronavirus Disease (COVID-19) pandemic. https://www.who. int/emergencies/diseases/novel-coronavirus-2019. Accessed Mar 2020 .

2. Wu F, Zhao S, Yu B, et al. A new corona virus associated with human respiratory disease in China. Nature 2020; 579: 265-9.

3. Ren X, Chen B, Hong Y, et al. The challenges in colorectal cancer management during COVID-19 epidemic. Ann Transl Med 2020; 8: 498 .

4. Hoffmann C. Treatment. In: Kamps BS, Hoffmann C (eds) COVID Reference, Edition 2020-2. Stein Hauser Verlag; Amedeo, Germany; 2020. Website www.covidreference.com. Accessed 12 Apr 2020.

5. Cao W, Fang Z, Hou G, et al. The psychological impact of the COVID-19 epidemic on college students in China. Psychiatry Res 2020; 11: 29-4.

6. Zheng $\mathrm{MH}$, Boni L, Fingerhut A . Minimally invasive surgery and the novel coronavirus outbreak: lessons learned in China and Italy. Ann Surg 2020; 272: e5-e6

7. Primatesta $\mathrm{P}$, Goldacre MJ . Inguinal hernia repair: incidence of elective and emergency surgery, readmission and mortality. Int J Epidemiol 1996; 25: 835-9

8. Rodríguez-Cuéllar E, Villeta R, Ruiz P. National project for the management of clinical processes. Surgical treatment of inguinal hernia. Cir Esp 2005; 77: 195-2

9. Góngora-Gómez, EM. Strangulated inguinal hernia. Cirugia Y Cirujanos 2012; 80: 357-7.

10. Ohene-Yeboah M, Dally CK. Strangulated inguinal hernia in adult males in Kumasi. Ghana Med J 2014; 48: 101-5.

11. The Hernia Surge Group, Simons MP, Smietanski M. et al. International guidelines for groin hernia management. Hernia 2018; 22: 1-165.

12. Orchard MR, Wright JA, Kelly A, et al .The impact of healthcare rationing on elective and emergency hernia repair. Hernia 2016; 20: 405-9.

13. Köckerling F, Köckerling D, Schug-Pass C. Elective hernia surgery cancellation due to the COVID-19 pandemic. Hernia 2020; 24: 1143-5.

14. D'Urbano F, Fabbri N, Koleva Radica M, et al. Emergency surgery in COVID-19 outbreak: Has anything changed? Single center experience. World J Clin Cases 2020; 8: 3691-6.

15. Martellucci J, Damigella A, Bergamini C, et al. Emergency surgery in the time of Coronavirus: the pandemic effect. Minerva Chir 2020; 10.23736/S0026-4733.20.08545-4.

16. Alp E, Bijl D, Bleichrodt RP, et al. Surgical smoke and infection control. J Hosp Infect 2006; 62: 1-5.

17. Muysoms F, Pawlak M, Reinpold W, et al. European Hernia Society (EHS) guidance for the management of adult patients with a hernia during the COVID-19 pandemic. Hernia 2020; 24: 977-3.

18. Lima DL, Pereira X, Dos Santos DC, Camacho D, Malcher F. Where are the hernias? A paradoxical decrease in emergency hernia surgery during COVID-19 pandemic. Hernia 2020; 24: 1141-2.

19. Stabilini, C, East B, Fortelny R, et al. European Hernia Society (EHS) guidance for the management of adult patients with a hernia during the COVID-19 pandemic. Hernia 2020; 24: 977-3. 